\title{
Rates of Food Transport down the Ambulacral Grooves and Through the Gut of Comanthus bennetti (Echinodermata: Crinoidea) Observed in Situ
}

\author{
D. L. Zmarzly and N. D. Holland*
}

Marine Biology Research Division, Scripps Institution of Oceanography, La Jolla, California 92093, USA

\begin{abstract}
Rates of food transport down the ambulacral groove of the arms and through the gut of the crinoid echinoderm Comanthus bennotti were measured in situon an Australian coral reef. For 10 adult crinords, the average rate of food transport down the ambulacral grooves was $4.2 \pm 1.0$ (SD) $\mathrm{cm} \mathrm{min-1}$ For 4 of these individuals, the gut clearance time averaged $2.4 \mathrm{~h}$; based on a gut length of $20 \mathrm{~cm}$, the rate of passage of material through the gut was $0.14 \mathrm{~cm} \mathrm{~min}^{-1}$
\end{abstract}

In his 1966 review, Anderson (p. 353) concluded that almost nothing was known about the nutritional biology of crinoid echinoderms. Since then, there have been some useful studies of suspension feeding and diet in crinoids (e.g Rutman and Fishelson, 1969; Meyer, 1973, 1979; La Touche, 1978; La Touche and West, 1980; Byrne and Fontaine, 1981). To date, however, there is no information on rates of food transport down the ambulacral grooves or through the guts of crinoids under field conditions. Such rates are best determined in situ, since, in our experience, some crinoids cease feeding in the laboratory (as judged by the absence of fecal pellets) even when seawater with suspended food is flowing through the aquarium.

We have measured rates of food transport in the stalkless crinoid Comanthus bennetti (J. Müller), observed directly by SCUBA diving. This species is favorable for field studies of feeding for several reasons: it is large when adult, with a central disc about $3.5 \mathrm{~cm}$ in diameter and arm lengths averaging $15 \mathrm{~cm}$; it is semi-sessile and well-exposed to view, perching on reef projections at relatively shallow depths; and it feeds during the day (Meyer, 1979). Food transport was measured in 11 adult Comanthus bennetti; arm lengths ranged from 12 to $16 \mathrm{~cm}$ in the smallest and largest specimens, respectively. Animals were observed between 3 and $11 \mathrm{~m}$ depth at North

- Addressee for reprint requests
Point, Lizard Island $\left(14^{\circ} 38^{\prime} \mathrm{S}, 145^{\circ} 30^{\prime} \mathrm{E}\right)$, Great Barrier Reef, Australia, from late morning through mid-afternoon on 17 and 21 June 1981. The water temperature was between $23^{\circ}$ and $24^{\circ} \mathrm{C}$, and the current, estimated subjectively, was slight to moderate.

We prepared bright orange, finely particulate food that would contrast with the relatively colorless natural food and feces of the crinoids. Tropical fish food (Shrimppeletts, Hartz Mountain, Harrison, New Jersey) was finely ground in a coffee grinder and sifted dry through a $35-\mu \mathrm{m}$ screen to remove larger particles. Similarly, orange chalk (Prang Non-Toxic Excello Squares, American Crayon Company, Sandusky, Ohio) was ground, added to a small volume of seawater and passed as a slurry through a $35-\mu \mathrm{m}$ screen to remove larger particles. We mixed $3 \mathrm{~g}$ of ground Shrimppeletts with $10 \mathrm{~g}$ of the chalk slurry and brought the mixture to $300 \mathrm{ml}$ by addition of seawater.

For field use, the well mixed suspension of orange food was divided among 6 plastic 50 -ml syringes. Approximately $20 \mathrm{ml}$ of the suspension was squirted into the seawater 10 to $20 \mathrm{~cm}$ up-current from each crinoid; the syringe tip was waved in a wide arc, dispersing the ejected contents as a cloud large enough to envelop the entire animal for roughly $10 \mathrm{~s}$. The cloud obscured the earliest stages of food capture, which involved the tube-feet and the ambulacral grooves of the pinnules (see Anderson, 1966). As the cloud cleared away, we observed orange material in the ambulacral groove of most arms. Sometimes an unbroken orange strand occupied much of the length of the ambulacral groove. More commonly, however, there were several short segments of orange material (a few millimeters long) distributed intermittently along the groove of a given arm. All the orange material in the ambulacral grooves traveled down the arms 
toward the central disc. The transport rate was measured by observing a segment of material a fourth of the way out the arm and recording the time required for the material to travel a distance of 10 consecutive pinnules on the same side of the armi this distance was later measured and found to be $2.4 \mathrm{~cm}$. For 10 of the crinoids (data for 1 specimen were missing), the average rate of transport was $4.2 \pm 1.0$ (SD) $\mathrm{cm} \mathrm{min}^{-1}$. At this rate, food in the ambulacral groove near the arm tip would require $3.6 \mathrm{~min}$ to travel all the way down the arm and reach the central disc of an adult specimen.

From the arm bases, the ambulacral grooves converge on the mouth, which is located on the oral side of the central disc. Comanthus bennetti, like other members of the family Comasteridae, has a relatively long gut for a crinoid (see diagram $27 \mathrm{E}$ on p. 66 of Hyman, 195.5). From the mouth: the gut makes 4 to 5 coils and ends at the anus on the oral side of the central disc. Feces are usually ejected as discrete, ovoid pellets, roughly $1 \mathrm{~cm}$ long; under field conditions, successive pellets are emitted at intervals ranging from 3 min to at least 30 min.

When we administered orange food, it presumably entered the mouth from the time the cloud reached the animal until the clearance of the ambulacral grooves 3.6 min later, thus resulting in a well-defined pulse label. Fig. 1 summarizes production of fecal pellets, showing whether they were unlabeled, lightly labeled or heavily labeled with orange chalk. Only crinoids Number 1 through 4 were observed producing unlabeled fecal pellets before orange labeled ones. The time required for gut clearance could thus be

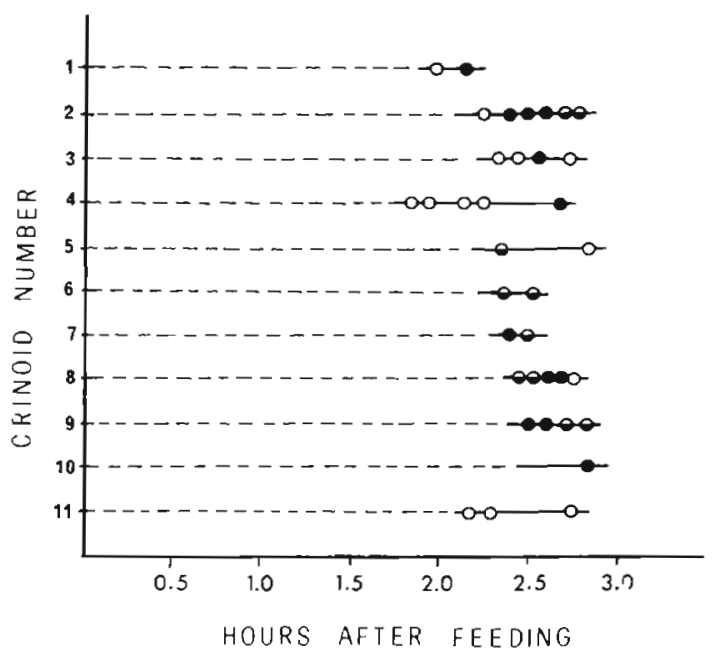

Fig. 1 Comanthus bennetti. Field observations on production of labeled fecal pellets to determine gut clearance time. Dashed lines: periods after administration of tabeled food when no observations were made; empty circles: unlabeled fecal pellets; filled and half-filled circles: dark orange and light orange fecal pellets, respectively established unequivocally and averaged $2.4 \mathrm{~h}$. Since an adult specimen of Comanthus bennetti has a gut approximately $20 \mathrm{~cm}$ long (based on measurements of a dissection of a specimen fixed in buffered formalin), the rate of passage through the guts of Crinoids 1 through 4 averaged $0.14 \mathrm{~cm} \mathrm{~min}^{-1}$. Our observations on Crinoids 5 through 10 began too late to detect unlabeled fecal pellets being produced before labeled ones (Fig. 1). Thus gut clearance could not be determined for these animals, although it did not exceed $2.8 \mathrm{~h}$ for any of them. A single individual (Number 11) produced anly unlabeled fecal pellets while we watched. Either this specimen failed to eat any labeled food or the gut clearance time was markedly shorter or longer than for the other ten animals in Fig. 1.

The only previous observation on gut clearance time in a crinoid was made on Andedon bifida by Dimelow (1958). She fed crinoids carmine particles in the laboratory and observed the production of red fecal pellets $1 \mathrm{~h}$ later. Such rapid passage through the gut of A. bifida is understandable, since this species, in comparison to Comanthus bennetti, has a much smaller adult size and a relatively short gut that makes only one coil between mouth and anus (see diagram $27 \mathrm{D}$ on p. 66 of Hyman, 1955)

Acknowledgements. We are deeply indebted to Director Barry Goldman and the staff of the Lizard Island Research Station of the Australian Museum for their hospitality and assistance while the present work was in progress. Our manuscript was improved by the critical reading of Ms. L. Z Holland.

\section{LITERATURE CITED}

Anderson, J. M. (1966). Aspects of nutritional physiology. In: Boolootian, R. A. (ed.) Physiology of Echinodermata. Wiley Interscience, New York, pp. 229-357

Byrne, M. Fontaine, A. R. (1981). The feeding behaviour of Florometra serratissima. Can. J. Zool. 59: 11-18

Dimelow, E. J. (1958). Some aspects of the biology of Antedon bifida (Pennant) with some reference to Neocomatella europaea. Doctoral Dissertation, Univ. Reading, Reading, England

Hyman, L. H. (1955). The invertebrates: IV. Echinodermata. McGraw-Hill, New York

La Touche, R. W. (1978). The feeding behaviour of the featherstar Antedon bifida (Echinodermata: Crinoidea). J. mar biol. Ass. U. K. 58: 877-890

La Touche, R. W., West, A. B. (1980). Observations on the food of Antedon bifida (Echinodermata: Crioidea). Mar. Biol. 60: $39-46$

Meyer, D. L. (1973). Feeding behavior and ecology of shallow-water unstalked crinoids (Echinodermata) in the Caribbean Sea. Mar. Biol. 22: 105-129

Meyer, D. L. (1979). Length and spacing of the tube feet in crinoids (Echinodermata) and their role in suspension feeding. Mar Biol. 51: 361-369

Rutman, J., Fishelson, L. (1969). Food composition and feeding behavior of shallow-water crinoids at Eilat (Red Sea). Mar Biol. 3: 46-57

Accepted for printing on August 5, 1981 